\title{
The Influence of Spatial Distribution of Transport Infrastructure on Transport Equity in China
}

\author{
Yuxin $\mathrm{Hu}^{*}$ \\ Huadong Engineering Corporation Limited, Hangzhou 311122, China. E-mail: 498133750@qq.com
}

Abstract: Urban transport infrastructure plays a key role and creates the basic condition in the development of the urban space. Meanwhile, urban gathering and diffusion bring the different urban spatial structure directly can change the spatial distribution of infrastructure. The influence of transport equity made by spatial distribution of urban transport infrastructure has obvious stages. At every stage, transport equity and spatial distribution of transport infrastructure mutually influence and interact. The intensity of the influence of transport equity by spatial distribution of transport infrastructure is not always the same, but sees a different situation with the simultaneous development of evolution stages.

Keywords: Transport Equity; Urban Spatial Structure; Urban Evolution Stages

\section{Transport equity}

The transport system must provide fair travel to each participate in social activities. The fair opportunity of using transport infrastructure within different social classes is the basic requirement of social equity, which can be detailed as two different transport equity: horizontal equity and vertical equity. The horizontal equity can be understood as the fairness and egalitarianism. Vertical equity is usually related to the social and environmental justice and social inclusion. In the vertical equity, individual and groups have access to resources with their different ability and needs ${ }^{[1]}$. The transport equity is supported to link the different social groups and accessibility with different travel demands, ability and the balance between travel cost and residents' income.

As a public goods, the transport infrastructure and its services should be fair and shared in the society and cannot be occupied by individuals or groups. The transport equity can be divided into two aspects: the equal opportunities and results of the spatial distribution of transport infrastructure as public goods within different social groups.

\section{The stage of spatial distribution of transport infrastructure}

Cheshire (1995) pointed out that the evolution of European urban transportation and spatial development can be divided into centralization, decentralization and urban cores these three stages ${ }^{[2]}$. In 1970, Adams linked the urban spatial patterns with the transport system and meanwhile, according to the transport infrastructure, defined spatial distribution form as four stages (walk and carriage era, tramcar era, automobile era and highway era $)^{[3]}$. Erickson thinks the spatial distribution of transport infrastructure should be regarded as three phases: specialization, diversification and multicentralization. Based on the development of urban space and transportation infrastructure, the author divides the spa-

Copyright @ 2020 Yuxin $\mathrm{Hu}$

doi: $10.18686 /$ utc.v6i4.95

This is an open-access article distributed under the terms of the Creative Commons Attribution Non-Commercial License

(http://creativecommons.org/licenses/by-nc/4.0/), which permits unrestricted non-commercial use, distribution, and reproduction in any medium, provided the original work is properly cited. 
tial distribution of transport infrastructure into three stages - the aggregated period, the dispersed period and the nodal period.

Northam then summarize this process as a S-type curve process for spatial distribution of transport infrastructure, as shown in Figure $\mathbf{1}^{[4]}$. The following para-

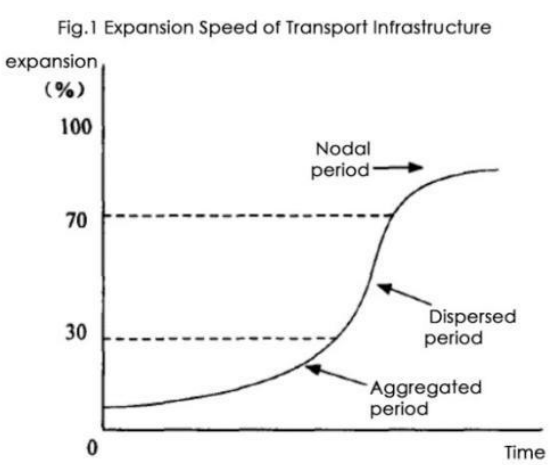

graphs take Shanghai as the main example to explain the stage-characterized influence of transport equity by spatial distribution of transport infrastructure in China.

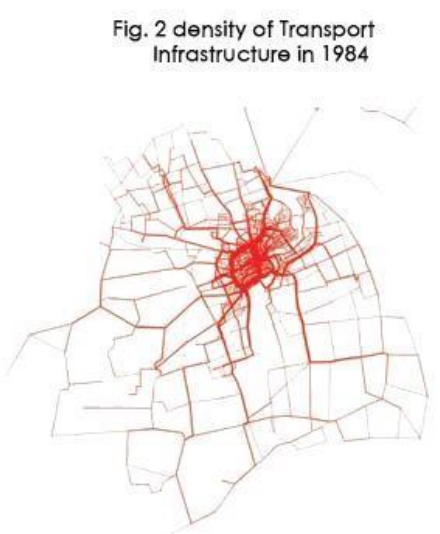

Figure 1-2. The S-type curve process for spatial distribution of transport infrastructure.

\section{Aggregated pattern}

From the early years since the founding of China to the 1970s, Shanghai was in a relatively slow development stage. The main transport infrastructure in Shanghai was relatively compact by 1984 , with a population of more than 10 million, as it is diagrammatically shown in Figure $2^{[5]}$. In the early period of economic reform before 1984, the highways between cities have not appear. The main area in which citizen travel was in the city center. As for the original low-income groups in Shanghai, some phenomena of transport inequity did occur: the inconvenient conventional public transport had some impact on their travel cost, accessibility of their jobs and basic services like health care, education. However, the lower-class groups seldom felt the transport inequity in their daily life, because the conventional public transport, automobile and the high percentages of the usage of bicycles can be used to meet the needs of citizens' daily trip within the limited urban area ${ }^{[6]}$. The increased construction of the prosperous central commercial zone provided many jobs and attracted a large sum of labor force settled in the city center. These factories and manufactories mixed with the services providers like schools, hospitals and also the massive amount of popu- lation as well as the transport infrastructure centered in the city center. People are not likely to feel serious transport inequity.

\section{Dispersed pattern}

With the increase of urban population and the improvement of urban transport conditions, the transport infrastructure has been gathered and then expanded continuously with the change of urban space. The reason is the original residential area and the spatial structure of the city center have been relatively stable and the newcomers have to settle down in the margin of the city. Due to the excessive fast expansion of urban space, the spatial distribution of transport infrastructure relocated to the urban marginal area, but is not followed by business, manufactures and services which provide basic services.

Transport infrastructure of the new peripheral urban area around the old city center ease the excessive concentration of employment opportunities and activities in the old city center in some extent. The travel departure places of residents scattering to the urban marginal area leads to the flow of transport to a new form of cross flow between the old and new rather than only in the old city center. Although it eases the transport pressure of the old city center, it led to the transport pressure surge in the 
marginal urban area, the transport system between them and the increasing long-distance travel demand. The stimulating of the increase in the proportion of utilize of private car results the widening gap between vulnerable travel groups and other travel groups.

Social vulnerable groups are likely to mainly refer to low-income groups. Subjecting to their own economic conditions, their tolerance of travel cost is relatively poor and they have relative fewer choices ${ }^{[7]}$. However, with the improvement of the economic development and the acceleration of the urbanization process, the number of private transport infrastructure like cars has increased rapidly, and the public transport infrastructure has been spreading to the suburbs. With the gradual marginalization of the residence, increasing travel distance and travel intensity, the vulnerable groups are not only generally faced with the housing, employment and other social exclusion problems but also faced with high travel costs, low level of accessibility.

Before the public transport infrastructure cannot afford the huge transport demand in the new marginal urban area and long-distance travel, the construction of the new marginal urban area increased the transport pressure of the intercity passages between the new and old and the transport inequality in the fast-urbanized areas has been intensified.

\section{Nodal pattern}

The nodal pattern is caused by the migration along the main thoroughfares for the spacious and quiet living conditions, which leads to the continuous expanding and enhancing of transport infrastructure in the city margin. The 1990 and 2000 Shanghai census data reveals the population of the central area of Shanghai showing a downward trend in this 10 year except Hongkou area. The marginal area outside the city center and suburbs except Chongming District saw the different growth of population, as shown in Table 1 (Shanghai Statistical Yearbook, 2005) ${ }^{[8]}$. The phenomenon in Shanghai that the population and transportation infrastructure spread from the center to the margin area was happened in the dispersed pattern (1984-1990) but then after 1990, transport infrastructure keeping a slow pace of growth changed to the nodal pattern as the relatively concentrated spatial distribution ${ }^{[9]}$.

Table 1 The Change of Population and Density in Shanghai

\begin{tabular}{|c|c|c|c|c|c|c|}
\hline \multirow{2}{*}{ Districts } & \multicolumn{2}{|c|}{ Year-end population } & \multirow{2}{*}{$\begin{array}{l}\text { Demographic } \\
\text { changes } \\
\text { (million) }\end{array}$} & \multicolumn{2}{|c|}{ Population density } & \multirow[t]{2}{*}{ Density change } \\
\hline & 1990 & 2000 & & 1990 & 2000 & \\
\hline Huangpu & 81.92 & 57.45 & -24.47 & 66920 & 46296 & .20625 \\
\hline Luwan & 42.04 & 32.89 & -9.15 & 52217 & 40859 & -11358 \\
\hline Jingan & 43.66 & 30.54 & -13.12 & 57303 & 40073 & -17230 \\
\hline Hongkou & 83.78 & 86.07 & 2.29 & 35682 & 36658 & 976 \\
\hline Xuhui & 76.71 & 106.46 & 29.75 & 14008 & 19442 & 5434 \\
\hline Changning & 60.16 & 70.22 & 10.06 & 15707 & 18335 & 2628 \\
\hline Putuo & 80.88 & 105.17 & 20.31 & 14752 & 19181 & 4429 \\
\hline Xiabei & 67.43 & 79.86 & 12.43 & 23659 & 27294 & 3635 \\
\hline Yangpu & 104.07 & 124.38 & 20.31 & 19963 & 20480 & 517 \\
\hline Minxing & 51.28 & 121.73 & 70.45 & 1383 & 3295 & 1912 \\
\hline Baoshan & 64.48 & 122.8 & 58.32 & 1519 & 2957 & 1438 \\
\hline Pudong & 143.73 & 240.23 & 96.5 & 2749 & 4596 & 1847 \\
\hline Jiading & 47.87 & 75.31 & 27.44 & 1043 & 1641 & 598 \\
\hline Nanhui & 70.29 & 78.51 & 8.22 & 1022 & 1142 & 120 \\
\hline Pengxian & 54.19 & 62.43 & 8.24 & 759 & 908 & 149 \\
\hline Songshan & 49.36 & 64.11 & 14.75 & 825 & 1060 & 235 \\
\hline Jinshan & 55.82 & 58.04 & 2.22 & 952 & 990 & 38 \\
\hline Qingpu & 45.66 & 59.59 & 13.93 & 676 & 882 & 206 \\
\hline Chongming & 72.81 & 64.98 & -7.83 & 699 & 624 & .75 \\
\hline
\end{tabular}

In the nodal pattern, the low-density distribution of land use and the public transport infrastructure is not conducive to the transport equity ${ }^{[10]}$. Due to the scattered spatial form of the new marginal urban area and the increasing demand of long-distance travel, the vulnerable groups who do not have the ability to travel by private 
cars can only rely on public transport infrastructure. However, it cannot always meet their travel demands because of the low density and poor coverage of public transport infrastructure in the inter-district passages between the new and old. Thus, the adverse condition of transport equity is influenced by the corresponding spatial distribution of transport infrastructure.

However, this detrimental impact does not affect the transport equity of vulnerable groups decisively. There are relatively centralized and integrated transport infrastructure in the new urban districts around the old city center $^{[11]}$. If there are no special needs, vulnerable groups can have the access to basic services and find jobs by using public transport or other vehicles like bicycles in the marginal districts in which they are living. Only when they need more advanced services, it may not be conducive to the vulnerable groups for the long-distance travel mode.

\section{Conclusion}

The long process of evolution of the spatial distribution of transport infrastructure experiences the aggregated pattern, the dispersed pattern and the nodal pattern, and the influence of transport equity are characterized by stages. The aggregated pattern sees the certain level of transport inequity but the vulnerable groups seldom felt it in their daily life. In the dispersed pattern, it is more obvious to observe phenomena of transport inequity among social groups. The relatively concentrated spatial distribution of transport infrastructure in nodal pattern positively influence the transport equity with the inte- grated transport infrastructure and the access to basic services and workplace in the marginal districts after the dispersed pattern.

\section{References}

1. Delbosc A, Currie G. Using Lorenz curves to assess public transport equity. Journal of Transport Geography $2011 ; 19(6)$ : 1252-1259.

2. Cheshire P. A new phase of urban development in Western Europe? The evidence for the 1980s. Urban Studies 1995; 32(7): 1045-1063.

3. Peng H, Lu H. Integrated relationship between land use and transportation based on GIS. $11^{\text {th }}$ World Conference on Transport Research 2007.

4. Zhang J. Reconsideration of the urbanization research in China. Chinese Geographical Science 2000; 10(2): 119-124.

5. Zhu Z. A comparison of the urban planning history between Beijing and Shanghai (in Chinese). City Planning Review 1989; (4): 31-37.

6. Davey JA. Older people and transport: Coping without a car. Ageing \& Society 2007; 27(1): 4965.

7. Xie Y, Lu H. Transport problems and countermeasures of social vulnerable groups (in Chinese). Comprehensive Transportation 2008; (9): 36-38.

8. Shanghai Bureau of Statistic. Forty years of new Shanghai (in Chinese). Beijing: National Bureau of Statistics of China; 1989. p. 370.

9. Zhang J. A study on the relationship between urban spatial structure and traffic demand in Shanghai (in Chinese) [master's thesis]. Shanghai: Shanghai Normal University; 2006.

10. Eisner S, Gallion A, Eisner S. The urban pattern. United States: John Wiley \& Sons; 1993.

11. Zhu H, Su Y, Li Q. The development and evolution of Shanghai comprehensive transportation system. Shanghai Urban Planning Review 2012; (2): 40-44. 